\title{
A Critique of Kellehear's Transcendent Society
}

\author{
Howard A. Mickel, Ph.D. \\ La Jolla, California
}

ABSTRACT: Allan Kellehear argued that the otherworld society envisioned in near-death experiences (NDEs) is similar to utopian societies. However, his cultural analysis, based on 9 Mormon NDEs, did not reflect the diversity of near-death visions from other cultures. I suggest that these Mormon NDEs were neither as utopian as Kellehear assumed nor representative of contemporary NDE reports, and that a more complete analysis would reveal a variety of NDEs and otherworld visions reflecting the experiencers' sociocultural background. Robert Bellah's model of religious evolution provides a model for charting the NDE's change over time and cultures, and allows us to differentiate the perennial features of the NDE from the transient culturally-determined ones - a first step in understanding the role of NDEs in the quest for an ideal society.

Most of the scholars I know who have investigated near-death experiences (NDEs) have been enormously impressed by the way NDErs have found their lives transformed by their experiences. But all of us who are impressed by the transformative capacities of the NDE face a common threat in the university: the tyranny of epistemology. As Suzanne Langer (1957) has noted, the major philosophical problem that all thinkers have faced since the times of Descartes is the bifurcation of knowledge into inner and outer, subjective and objective. $\mathrm{Hu}$ man beings can have thoughts, ideals, visions, revelations, feelings,

Howard Mickel, Ph.D., formerly Chairman of the Department of Religion at Wichita State University, is currently Director of the Theta Project, an educational and research effort focusing on near-death and related experiences. Reprint requests should be addressed to Dr. Mickel at 632 Sea Lane, La Jolla, CA 92037. 
intuitions, but it is the scientific method that confirms what is empirically "real."

Those of us in the field of near-death studies know the frustration of sensing the importance of this transformative human experience and yet having our work discounted, dismissed, or even ridiculed because it is subjective like a dream or a hallucination, and not "real." Allan Kellehear's article will undoubtedly attract the attention of near-death researchers because he tried to bypass the "tyranny of epistemology" by not addressing the reality of NDE reports, but rather to show that the ideals found in reports of the transcendent society may reawaken the pursuit of an ideal society in our own time. This is a very important and legitimate task.

Kellehear attempted a cultural analysis of the otherworld society in NDE visions and compared it with five ideal societies. He found it came closest to the utopian society. Finally, he showed that the narratives of the transcendent society may reawaken and inspire our efforts to create an ideal society in our day. The ideals found in the NDE include harmony, order, love, cooperation, service, and learning, which may inspire us at a time when moral and social disorder are rampant and growing.

My major criticism of Kellehear's program is in the way he carried out his task; that is, I am concerned about his method. He undertook a cultural analysis of the otherworld(s) that appear in the NDE; but he never did that satisfactorily. He drew mainly on Craig Lundahl's work, which focused on a review of modern NDEs and nine selected, mostly 19-century Mormon NDEs. This is a rather narrow data base for what one would expect to be a global perspective on the NDE. Those of us in other disciplines need the historian, ethnologist, anthropologist, and sociologist to research NDEs throughout history and in other parts of the world and provide a cultural analysis that would show the similarities and differences between these NDEs.

Such an analysis, I argue, would show that there are varieties of NDEs around the world and not the NDE; it would show there are a variety of otherworld visions and not the transcendent society. This analysis would show that there are widespread similarities among NDEs around the world: persons on the brink of death journey to another world; they are accompanied by guides; they see departed loved ones; they are told they must go back; they return changed with a message for others.

But the second thing this cultural analysis would show is that the visionary perceives the otherworld in a way consistent with his or her social and cultural background. Members of the Oglala Sioux report 
being transported to another world where the six grandfathers preside and the events they see are similar to what they have learned in their lifetime through story, song, and dance (Neihardt, 1961). Natives from Melanesia on the verge of death describe visiting a world that parallels their belief in the cargo cult (Counts, 1983). Visionaries from northern India report visiting an otherworld where they receive judgments from sacred and divine personages in their religious tradition (Pasricha and Stevenson, 1986). Medieval Christian visions of the otherworld reflect the doctrines of the Catholic Church and its institutional and social organization (Zaleski, 1987). Mormons describe journeys to an otherworld that is consistent with Mormon doctrine, teaching, and organization (Lundahl, 1981-82).

When modern persons are near death, they report journeys to an otherworld where the assumptions of democracy, acceptance, and selfknowledge prevail, according to Carol Zaleski, because modern neardeath narratives "are no more free of cultural influence than those of less pluralistic eras" (1987, p. 190). She observed that contemporary near-death researchers have missed these assumptions because they have been too immersed in their own age.

If Kellehear had provided this global perspective of the NDE, we could have seen more clearly the great variety of near-death visions of the otherworld; and then we might have seen how this global perspective could help us find an orientation in our personal lives and society. But Kellehear has focused too narrowly on two quite different types of NDE: the 19th-century Mormon NDE and the modern NDE as initially described by Raymond Moody (1975). He assumed, following Lundahl's lead, that the Mormon and the modern NDE are quite similar. He appears to have been too ready to find ideals, principles, or "messages" in the NDE that might inspire persons who face social disorder.

The selection of the Mormon NDE out of the great variety of NDEs that have occurred in history and in various cultures suited Kellehear's purpose very well, for he needed to find a strong sense of social order to stem the tide of contemporary social disorder. The Mormon Church was an ideal choice because it is arguably the most highly socially organized and efficient religious denomination in the United States. Kellehear wrote that the transcendent society is a place that "is highly organized, and conversely eschews disorder and confusion" (p. 82). Social order is a desirable ideal in the modern world; in fact, it may not be so much an ideal as a precondition for any society.

What Kellehear did not make clear, explicit, and detailed was that the Mormon vision of the otherworld was a Mormon heaven, not a modern, Moody-type vision of the otherworld. Words like "order" are 
general, abstract, empty terms that seem desirable, but the "order" Mormons saw in their visions reflected the "order" that came from the revelations of their prophets and is quite different from that in a democratic society. The Mormons are a highly organized group because historically the Mormon Church grew up outside of and in contention with the United States government.

Mormons believe themselves to be following the teaching of the Doctrine and Covenants (1880/1979), a community of God's chosen people under an egalitarian economic order called the Law of Consecration and Stewardship. The Church organizes its affairs through the hierarchical offices of the Bishop, Deacon, Elder, Patriarch, and Apostle, and is led by a President who can speak as a divinely inspired Prophet. Up until 1890 Mormon family life was polygamous, each man having the option of several wives who were subordinate to the husband and who could not hold the office of priest.

In Mormon teaching and life the words "order," "service," and "learning" are imbedded in a far different context than the modern reader might imagine. For example, among Lundahl's Mormon cases was that of Jedidiah M. Grant, who in 1856 had a vision of the otherworld and "saw the order of righteous men and women; beheld them organized in their several grades. . . . organized in family capacities" (Lundwall, n.d., pp. 71-72, cited in Lundahl, 1981-82, p. 322). Grant saw them organized in family capacity because Mormons are married for "time and eternity"; eternal marriage is not taught by mainline Catholics and Protestants. Mormon order is based on a theocratic perspective that many modern people would consider authoritarian, chauvinistic, and inconsistent with what Robert Bellah (1964) called the modern temper: the feeling in the modern world that the individual is responsible for his or her decisions.

But Kellehear's cultural analysis did not include the cultural roots of Mormonism. He made an amalgam of the Mormon otherworld vision and the modern Moody-type otherworld visions, and out of them created "the transcendent society." But these are actually two quite different and even conflicting views of social organization. For example, Kellehear wrote that "the transcendent society is not linked to any ideology of salvation. That is, entry into that ideal form of society is not dependent on membership in any religious movement" (p. 87). That may be true for the modern vision of the otherworld, the transcendent society, and the utopian society, but it is not true of the Mormon vision of the otherworld. In his 1856 Mormon otherworld vision Grant saw no wicked spirits, but he saw families that were not permitted to live 
together, because they had not honored their calling (Journal of Discourses, 1882/1966).

Mormons in otherworld visions are told to do ordinance work that includes baptizing deceased relatives in a Mormon temple. In Mormon teaching, progress is linked to Mormon doctrine, teaching, and ritual; this perspective is quite different from the general moral progress in the modern, Moody-type NDE. As Zaleski pointed out, modern NDE narratives are shaped by a democratic mood: they "advocate ... an individualistic, anti-institutional, humanistic ideal" (1987, p. 190). Kellehear has presented a mixture of two quite different social organizations in the otherworld and tried to pass it off as "the transcendent society." He selected those features of NDEs that fit his transcendent society and ignored, minimized, or misrepresented many features that did not.

For example, Kellehear summarized Dorothy Counts's research on Melanesian NDEs by writing that their otherworld is a beautiful, wellordered place: people there are "described as working, constructing buildings or participating in traditional song and dance" (p. 82). All of this fits Kellehear's beautiful transcendent society; but this is not Counts's understanding of the Melanesian otherworld:

... the land of the dead is perceived as a happy place. It is, however, not the pleasant garden reported by Moody (1975) and by Osis and Haraldsson (1977). Instead it is a land that is described as having factories and wage employment. It has an appearance that reminds me of the view approaching Los Angeles from the air. . . Paradise, the land of the dead, is a place of factories, automobiles, highways, airplanes, European houses and buildings in great numbers, and manufactured goods. One man's smoggy freeway is another man's heaven! (Counts, 1983, p. 130)

The complex beliefs that shape the Melanesian vision of the otherworld are based on the cargo cult, which sees white people as spirit beings who send cargo planes filled with technological wonders from another world. A detailed socioanthropological analysis of the cargo cult would reveal how these beliefs are reflected in the Melanesian conception of the otherworld. Kellehear did not provide such a cultural analysis, but instead skimmed off what was similar to "the transcendent society" and in the process misrepresented the Melanesian vision of the otherworld.

Another case in which Kellehear ignored data that conflict with his thesis about the transcendent society involved the study of 16 NDEs 
from northern India reported by Satwant Pasricha and Ian Stevenson (1986). A typical case involved an Indian who "is taken in hand by 'messengers' and brought before a man or woman who is often described as having a book or papers that he or she consults. A mistake is discovered. The wrong person has been 'sent for,' and this person is then brought back by the messengers to his or her terrestrial life" (Pasricha and Stevenson, 1986, p. 167). Kellehear did not mention these Indian NDEs, perhaps because the transcendent society is a wellordered society, while these Indian cases suggest disorder and confusion in the otherworld. However, the Indian cases are more numerous than the nine Mormon cases he used for his description of the transcendent society.

Why did Kellehear select the nine Mormon cases and Lundahl's review of modern NDEs? There are other studies that vividly describe the otherworld: native American NDEs (Neihardt, 1961), Pasricha and Stevenson's NDE cases from northern India, Zaleski's medieval Christian NDEs, the Gallup nationwide survey of modern NDEs (Gallup and Proctor, 1982), and others. It appears to me that he selected these cases because the social order and harmony seen in the Mormon otherworld vision are inspiring resources for offsetting the social disorganization and disruption in modern society. In addition, the cultural influences on the Mormon accounts are not as visible as, for example, on medieval Christian NDEs.

What Kellehear has done by compounding Mormon visions of the otherworld and modern, Moody-type NDEs is to highlight the contemporary dilemma. It is possible to have a high degree of social order and control in a closed Mormon society with divinely inspired leadership, but those rigidities are felt to be too constraining by modern persons who sense that self-responsibility is the only basis for contemporary decision-making. On the other hand, the individualistic, antiinstitutional, humanistic, and accepting ideals of the modern, Moodytype NDE resonate with the democratic sense of self-responsibility; but, as Plato warned long ago they also contain the threat of mobocracy and social anarchy.

Another dilemma Kellehear faced centers on the inspiring ideals of love, harmony, and cooperation. If these ideals of the transcendent society are the same that exist in the teachings of the Mormon Church and in a social system that has endorsed the subordination of women and, historically, has had difficulty giving blacks full status as members of the Church, then they may not be adequate to provide the social renewal for which Kellehear hoped. The Roman Catholic social teach- 
ing and that of prominent Protestant ethicists like Reinhold Niebuhr (1953) maintain that love is not enough in making social decisions. Love must be coupled with justice to make the deliberate, calculated policies that are required in society.

I see Kellehear's program as a quasi-religious quest characteristic of modern society. As Bellah wrote: "The search for adequate standards of action, which is at the same time a search for personal maturity and social relevance, is in itself the heart of the modern quest for salvation, if I may divest that word of dualistic association" $(1964$, p. 373). Kellehear's programmatic proposal to find ideals in the NDE for personal and social guidance is a modern and relevant quest for secular salvation. My criticism of his proposal is in his selection of data to identify the transcendent society and his interpretation of those data.

As I mentioned above, I believe that a global cultural analysis of NDEs in history and in various cultures would reveal a variety of NDEs and otherworld visions, and not the NDE or the transcendent society. Further, I suggest that Bellah's article on "Religious Evolution" (1964) provides a useful model for classifying the stages NDEs have gone through in history. Bellah's five evolutionary stages of religion-primitive, archaic, historic, early modern, and modernprovide a useful model for describing how NDEs change throughout history and how they reflect the social and cultural context of the NDEr.

Using Bellah's model has four advantages. First, it is based on four decades of research into the sociology of religion by an eminent American sociologist. Second, it utilizes the critical historical, Biblical, and theological research of the last 200 years. Third, the evolutionary stages in the model are not based on speculation, like those of Georg Hegel and Karl Marx, but are anchored in actual observations of what has happened to religious beliefs and organizations through history. Fourth, granted that near-death studies is a multidisciplinary field, the NDE is best seen in the context of religious studies alongside mystical experience, visionary experience, conversion, and other phenomena that have been the special province of religious studies.

With a comprehensive global perspective on the NDE, we will be able to see how the NDE evolved and developed in history and how social and cultural contexts influence the NDEr's perception of the otherworld. Then we may be able to discover which features of the NDE are perennial and which are transient. Only then will we understand what the images of the NDE have to offer in terms of resources in finding an orientation that is vital and healing. 


\section{References}

Bellah, R.N. (1964). Religious evolution. American Sociological Review, 28, 353-374.

Counts, D.A. (1983). Near-death and out-of-body experiences in a Melanesian society. Anabiosis: The Journal of Near-Death Studies, 3, 115-135.

Doctrine and Covenants. (1979). Salt Lake City, UT: Church of Jesus Christ of LatterDay Saints. (Original work published 1880)

Gallup, G., Jr., and Proctor, W. (1982). Adventures in immortality: A look beyond the threshold of death. New York, NY: McGraw-Hill.

Journal of Discourses. (1966). Los Angeles, CA: General Printing and Lithograph. (Original work published 1882)

Langer, S.K. (1957). Philosophy in a new key: A study in the symbolism of reason, rite and art (3rd ed.). Cambridge, MA: Harvard University Press.

Lundahl, C.R. (1981-82). The perceived other world in Mormon near-death experiences: A social and physical description. Omega, 12, 319-327.

Lundwall, N.B. (n.d.). The vision. Salt Lake City, UT: Bookcraft.

Moody, R.A., Jr. (1975). Life after life. Covington, GA: Mockingbird Books.

Neihardt, J.G. (1961). Black Elk speaks. Lincoln, NE: University of Nebraska Press.

Niebuhr, R. (1953). The nature and destiny of man. New York, NY: Charles Scribner's Sons.

Osis, K., and Haraldsson, E. (1977). At the hour of death. New York, NY: Avon.

Pasricha, S., and Stevenson, I. (1986). Near-death experiences in India: A preliminary report. Journal of Nervous and Mental Disease, 174, 165-170.

Zaleski, C. (1987). Otherworld journeys: Accounts of near-death experience in medieval and modern times. New York, NY: Oxford University Press. 